\title{
VALIDATED LC-MS/MS METHOD FOR THE DETERMINATION OF TADALAFIL - A COMPETITIVE PHOSPHODIESTERASE 5 INHIBITOR (PDE5) - FROM HUMAN PLASMA
}

\author{
RÓBERT TŐTŐS ${ }^{a^{*}}$, JÓZSEF BALÁZSI ${ }^{b}$
}

\begin{abstract}
The purpose of this study was the development and validation of an LC-MS/MS method, for the determination of tadalafil from human plasma. The sample workup involved a simple protein precipitation procedure. A core/shell type analytical column $(50 \times 2,1 \mathrm{~mm}, 2.6 \AA)$ was used with $\mathrm{C} 18$ stationary phase. The mobile phase consisting of $30 \%$ acetonitril and $70 \%$ water provided good peak shape, accuracy and precision (stable ionization). The mass spectrometer was operated in positive electrospray ionization mode for analyte and internal standard. The following parameters were evaluated for validation purpose: selectivity, sensitivity, matrix effect, anticoagulant effect, linearity, precision and accuracy, recovery, short and long term analyte/IS stability in solvent/matrix and carryover. The validated calibration range was 22.2-1111.3 ng/ml. The correlation coefficient $\mathrm{R}^{2}$ was at least 0.9995 in all validation batches. The validated method has been successfully used for the evaluation of bioequivalence of generic tadalafil $20 \mathrm{mg}$ formulations.
\end{abstract}

Keywords: tadalafil, phosphodiesterase 5 inhibitor, method validation, bioequivalence trial, LC-MS/MS

\section{INTRODUCTION}

Tadalafil, (6R,12aR)-6-(1,3-benzodioxol-5-yl)-2,3,6,7,12,12a-hexa-hydro2-methylpyrazino[1',2':1,6]pyrido[3,4-b]indole-1,4-dione with the empirical formula $\mathrm{C}_{22} \mathrm{H}_{19} \mathrm{~N}_{3} \mathrm{O}_{4}$ (Figure 1) is a reversible cyclic guanosine

\footnotetext{
a Babeş-Bolyai University, Faculty of Chemistry and Chemical Engineering, Biocatalysis and Biotransformation Research Centre, 11 Arany János str., RO-400028, Cluj-Napoca, Romania

b PharmacoKinetics SRL, 373 E/4 Corunca, RO-547367, Mures county, Romania

*Corresponding author: totosr@chem.ubbcluj.ro
} 
monophosphate(cGMP)-specific phosphodiesterase Type 5 inhibitor indicated for the treatment pulmonary arterial hypertension, benign prostatic hyperplasia but mainly used for the treatment of erectile dysfunction (impotence) [1, 2, 13]. Tadalafil acts as a muscle relaxant of blood vessels, increasing blood flow to particular part of the human body.

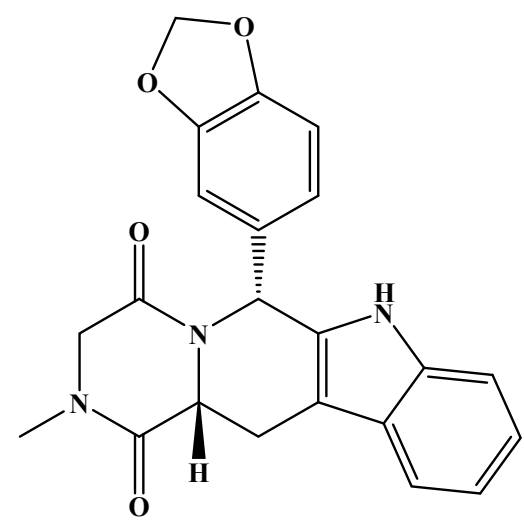

Figure 1. Structure of tadalafil

\section{RESULTS AND DISCUSSION}

\section{Determination of acquisition parameters}

There are various methods known in the literature for the determination of tadalafil in human blood, plasma or urine [3, 4, 7-9], animal plasma [5] or pharmaceutical formulations/dietary supplements [11], using LC-MS/MS methods.

The $\mathrm{m} / \mathrm{z}$ transitions used for multiple reaction monitoring (MRM) [6, 10, 12] were chosen based on the spectra from Figures 2 and 3 . The monitored transitions should not interfere in their $\mathrm{m} / \mathrm{z}$ value, specific for a given analyte. Their intensity should be convenient for the qualifiers, and the qualifier/ quantifier ratio should remain stable over the whole calibration range and in time. Taking into account the considerations above the following transitions were chosen for the quantitative assay method:

Tadalafil: $\mathrm{m} / \mathrm{z} 390.2 \rightarrow 268.1$, (390.2 $\rightarrow 135.0$ qualifier ion) CE $15 \mathrm{~V}$,

Losartan (IS): $\mathrm{m} / \mathrm{z} 423.2 \rightarrow 207.1$ (423.2 $\rightarrow 377.2$ qualifier ion) CE $15 \mathrm{~V}$. (CE - Collision Energy) 
VALIDATED LC-MS/MS METHOD FOR THE DETERMINATION OF TADALAFIL A COMPETITIVE PHOSPHODIESTERASE 5 INHIBITOR (PDE5) - FROM HUMAN PLASMA

For analyte and IS (Internal Standard) the single charged molecular ions were used as precursors.

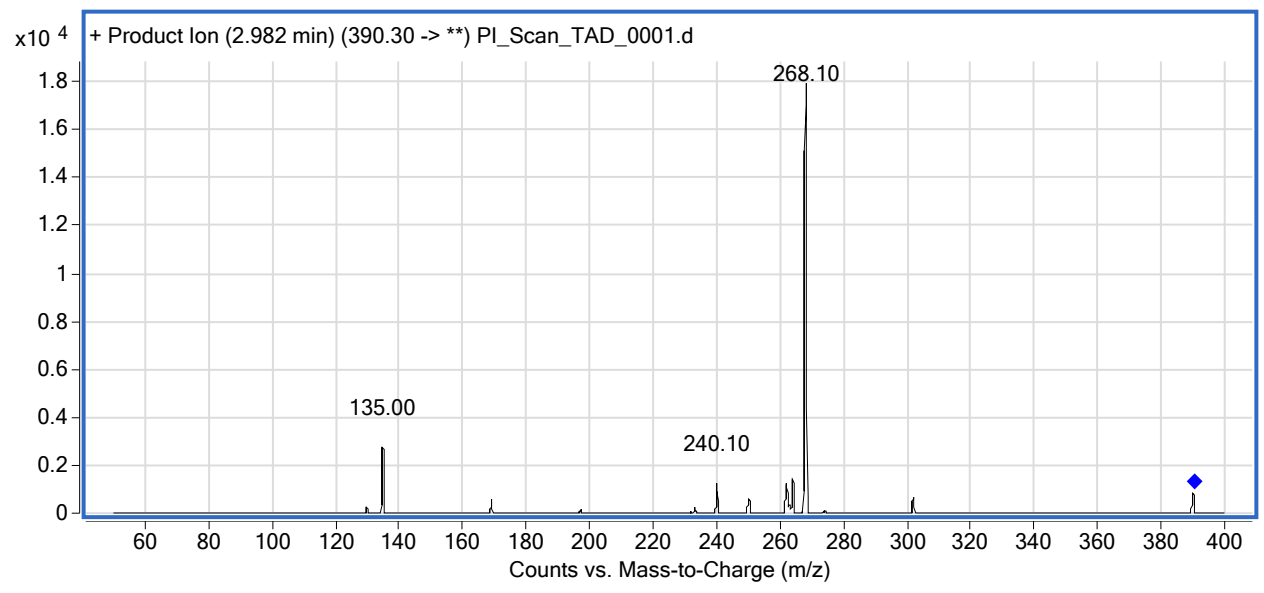

Figure 2. ESI (+) Spectrum of Tadalafil

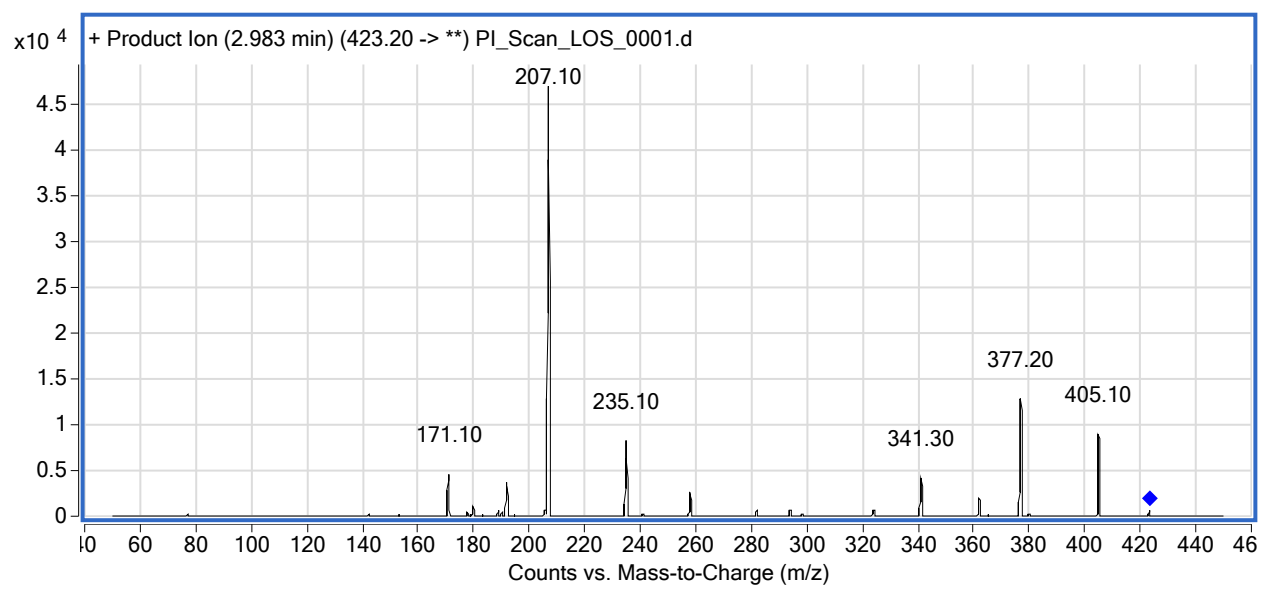

Figure 3. ESI (+) Spectrum Losartan (IS)

Figure 4 shows a typical MRM total ion chromatogram for an ULOQ (upper limit of calibration) sample. The analyte and IS are practically coeluting at $3.0 \mathrm{~min}$. Values are back calculated concentrations for each analyte. 


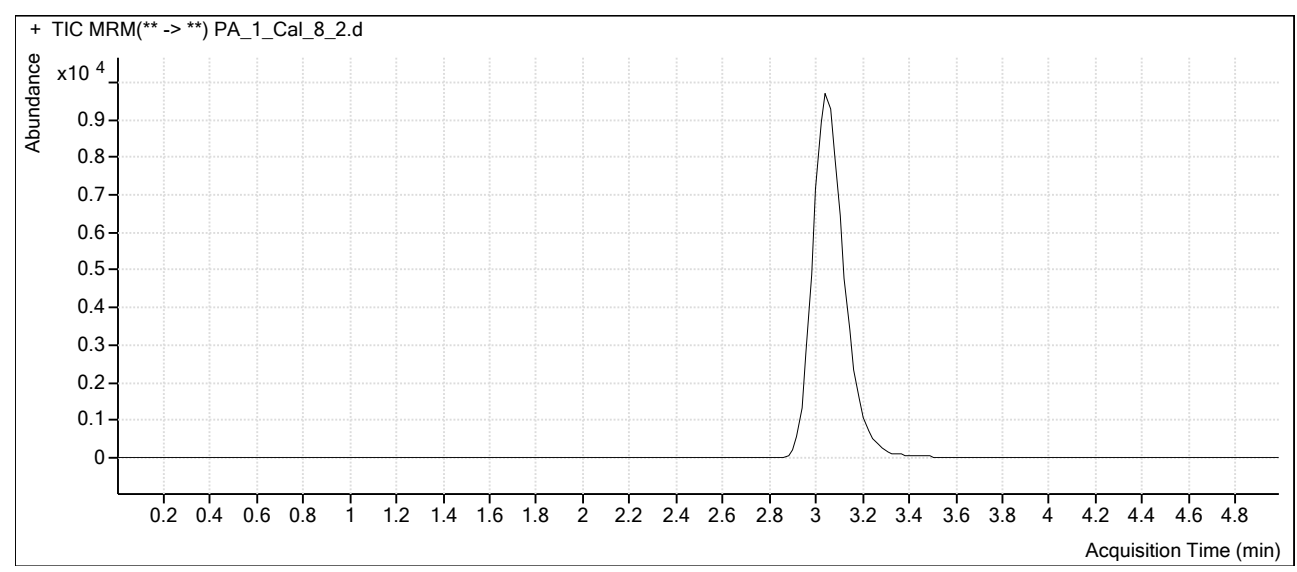

Figure 4. MRM chromatogram of Cal8 (tadalafil $1111.3 \mathrm{ng} / \mathrm{ml}$, Losartan $39.9 \mathrm{ng} / \mathrm{ml}$ )

The use of the co-eluting internal standard leads to a minimization of the matrix effect, and it's a convenient alternative to the stable isotope labeled tadalafil. Moreover, it is easily soluble in the sample solvent resulting after plasma protein precipitation (methanol:water 4:1).

It's noticeable, that no significant spectral response has been observed at the retention time of the analyte/IS in matrix blank samples (Figure 5).

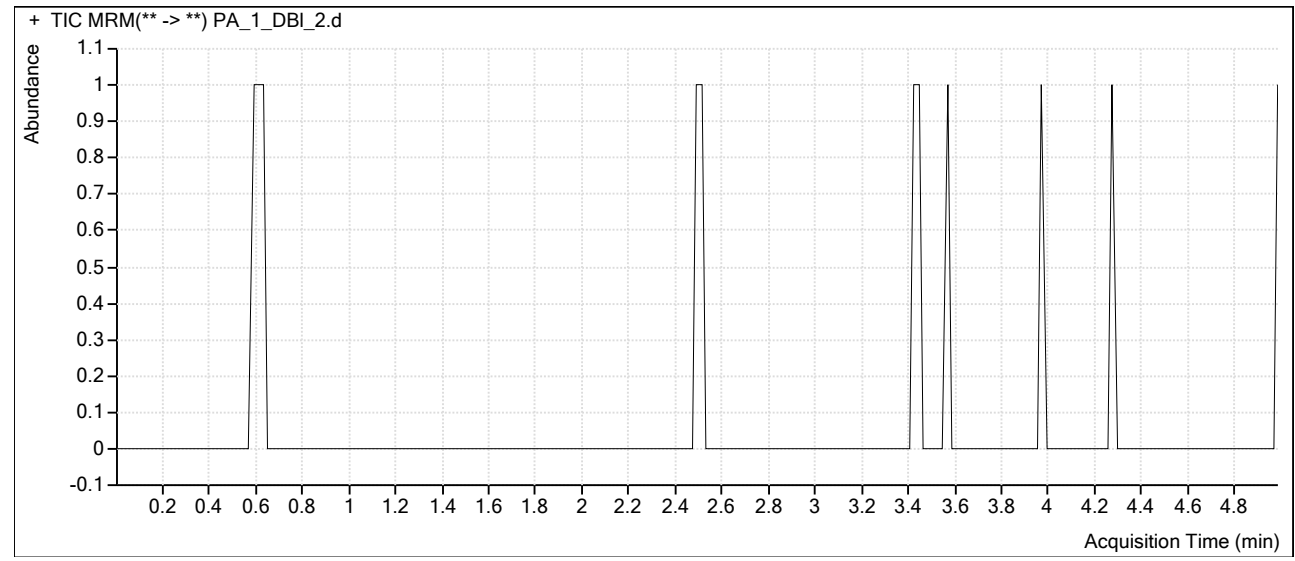

Figure 5. MRM chromatogram of DBI2 (matrix blank $0 \mathrm{ng} / \mathrm{ml}$ analyte/IS) 
VALIDATED LC-MS/MS METHOD FOR THE DETERMINATION OF TADALAFIL -

A COMPETITIVE PHOSPHODIESTERASE 5 INHIBITOR (PDE5) - FROM HUMAN PLASMA

\section{Bioanalytical method validation}

The analytical method was validated according to the EMEA/CHMP/ EWP/192217/2009 Guideline on validation of bioanalytical methods [14].

The tested parameters were: selectivity, sensitivity, matrix effect, anticoagulant effect, intra/interbatch precision and accuracy, recovery, short/ long term stability of stock solutions of analyte, short term stability of working solutions of analyte, tabletop stability in biological matrix, freeze thaw stability in biological matrix, injector/autosampler stability of the processed samples, stability during delayed processing (worst case scenario), dilution qualification, analyte and internal standard carryover. All tests were performed using 6 replicates at the mentioned QC (Quality Control) concentration levels.

The calibration curve range is established according to literature data about plasma concentrations of the analyte. $\mathrm{C}_{\max }$ average from literature for Tadalafil was found to be $\sim 450-500 \mathrm{ng} / \mathrm{ml}$, after administration of a $20 \mathrm{mg}$ dose $[2-4,8]$. Table 1.

A summary of main results of validation batches is presented in

The validated calibration range was $22.2-1111.3 \mathrm{ng} / \mathrm{ml}$. The calibration curves were obtained using a linear weighted $(1 / x)$ regression analysis of the peak area ratio (analyte/internal standard) versus the nominal concentration of the calibration standards. The lower limit of quantitation was set smaller than $5 \%$ of expected average $C_{\max }$ values.

Linearity summary results for tadalafil are presented in Table 2 . The limit of quantitation was $22.2 \mathrm{ng} / \mathrm{ml}$ and the linear dynamic range of the curve was from 22.2 to $1111.3 \mathrm{ng} / \mathrm{ml}$.

\section{Summary of method validation}

Table 1. Bioanalytical method validation summary for tadalafil

\begin{tabular}{|l|l|}
\hline Calibration concentrations $(\mathrm{ng} / \mathrm{ml})$ & $22.23,22.23,44.45,83.35,166.70,333.40$, \\
& $611.23,833.50,1111.33,1111.33(\mathrm{ng} / \mathrm{ml})$ \\
\hline Lower limit of quantitation $(\mathrm{ng} / \mathrm{ml})$ & $\mathrm{LLOQ}, 22.23 \mathrm{ng} / \mathrm{ml}$, Accuracy $97.91 \%, \mathrm{RSD}$ \\
& 2.98 \\
\hline QC Concentrations $(\mathrm{ng} / \mathrm{ml})$ & $\mathrm{LLOQ}-\mathrm{QC}, \mathrm{LQC}, \mathrm{MQC}, \mathrm{HQC}$ \\
& $22.23,44.45,333.40,833.50(\mathrm{ng} / \mathrm{ml})$ \\
\hline Between-run accuracy (\%) & LLOQ-QC, LQC, MQC, HQC \\
& $99.74,99.50,99.11,99.30$ \\
\hline Between-run precision (RSD) & LLOQ-QC, LQC, MQC, HQC \\
& $2.18,2.82,3.76,3.97$ \\
\hline IS normalized Matrix factor (MF) & $0.96(1.32)$ \\
RSD & \\
\hline
\end{tabular}




\begin{tabular}{|c|c|}
\hline Recovery (\%) & \begin{tabular}{|lll} 
LQC, & MQC, & HQC \\
100.38, & 98.29, & 97.14 \\
\end{tabular} \\
\hline $\begin{array}{l}\text { Long term stability of stock solution and } \\
\text { working solutions (Observed change \%) }\end{array}$ & $\begin{array}{l}\text { Confirmed up to } 20 \text { days at }+4{ }^{\circ} \mathrm{C} \\
\text { LQC Stab. } 111.86 \text {, change }+11.86 \% \\
\text { HQC Stab. } 105.35 \text { change }+5.35 \%\end{array}$ \\
\hline $\begin{array}{l}\text { Short term stability in biological matrix at } \\
\text { room temperature or at sample processing } \\
\text { temperature. (Observed change \%) }\end{array}$ & $\begin{array}{l}\text { Confirmed up to } 23.58(3) \text { h } \\
\text { LQC Stab. 106.13, change }+6.13 \% \\
\text { HQC Stab. 106.66, change }+6.66 \%\end{array}$ \\
\hline $\begin{array}{l}\text { Long term stability in biological matrix } \\
\text { (Observed change \%) }\end{array}$ & $\begin{array}{l}\text { Confirmed up to } 134 \text { days at }-50^{\circ} \mathrm{C} \\
\text { LQC Stab. } 106.38 \text {, change }+6.38 \% \\
\text { HQC Stab. } 103.23 \text { change }+3.23 \%\end{array}$ \\
\hline $\begin{array}{l}\text { Autosampler storage stability } \\
\text { (Observed change \%) }\end{array}$ & $\begin{array}{l}\text { Confirmed up to } 73.38(3) \mathrm{h} \\
\text { LQC Stab. 103.53, change }+3.53 \% \\
\text { HQC Stab. } 100.59 \text {, change }+0.59 \%\end{array}$ \\
\hline $\begin{array}{l}\text { Freeze and thaw stability } \\
\text { (Observed change \%) }\end{array}$ & $\begin{array}{l}-50^{\circ} \mathrm{C}, 3 \text { cycles } \\
\text { LQC Stab. } 100.77 \text {, change }+0.77 \% \\
\text { HQC Stab. } 99.01 \text {, change }-0.99 \%\end{array}$ \\
\hline Dilution integrity & $\begin{array}{l}\text { Concentration diluted (2-fold) } \\
99.97 \% ; \text { RSD } 1.91 \% \\
\text { Concentration diluted (4-fold) } \\
97.73 \% ; \text { RSD } 4.35 \%\end{array}$ \\
\hline
\end{tabular}

$P A$ - Precision and Accuracy batch LLOQ-QC/LQC/MQC/HQC - Lower Limit of Quantitation/Low/Medium/High Quality Control sample

Table 2. Linearity summary results for tadalafil

\begin{tabular}{|c|c|c|c|c|}
\hline Calibration level & $\begin{array}{c}\text { Nominal conc. } \\
(\mathrm{ng} / \mathrm{ml})\end{array}$ & $\begin{array}{c}\text { Mean conc. } \\
(\mathrm{ng} / \mathrm{ml}) \mathrm{n}=6\end{array}$ & $\begin{array}{c}\text { RSD } \\
\%\end{array}$ & $\begin{array}{c}\text { Accuracy } \\
\%\end{array}$ \\
\hline Cal_1_1 & 22.23 & $22.21 \pm 0.60$ & 2.70 & 99.92 \\
\hline Cal_1_2 & 22.23 & $22.15 \pm 0.54$ & 2.43 & 99.64 \\
\hline Cal_2 & 44.45 & $45.24 \pm 0.55$ & 1.22 & 101.78 \\
\hline Cal_3 & 83.35 & $83.94 \pm 0.77$ & 0.92 & 100.70 \\
\hline Cal_4 & 166.70 & $162.58 \pm 3.25$ & 2.00 & 97.53 \\
\hline Cal_5 & 333.40 & $335.99 \pm 4.30$ & 1.28 & 100.78 \\
\hline Cal_6 & 611.23 & $603.09 \pm 8.76$ & 1.45 & 98.67 \\
\hline Cal_7 & 833.50 & $841.03 \pm 2.53$ & 0.30 & 100.90 \\
\hline Cal_8_1 & $1,111.33$ & $1103.99 \pm 6.81$ & 0.62 & 99.34 \\
\hline Cal_8_2 & $1,111.33$ & $1119.52 \pm 8.15$ & 0.73 & 100.74 \\
\hline
\end{tabular}


VALIDATED LC-MS/MS METHOD FOR THE DETERMINATION OF TADALAFIL -

A COMPETITIVE PHOSPHODIESTERASE 5 INHIBITOR (PDE5) - FROM HUMAN PLASMA

\section{CONCLUSIONS}

A rapid and robust method has been developed and validated for the determination of tadalafil in human plasma. The quantitation was performed on an Agilent 1200 series HPLC system, coupled to an Agilent 6410 triple quadrupole mass spectrometer, using electrospray ionization technique. The components were detected in positive ionization mode. The method was successfully used for the evaluation of bioequivalence of a generic formulation of tadalafil $20 \mathrm{mg}$ film-coated tablets versus Cialis ${ }^{\circledR} 20$ mg film-coated tablets, Eli Lilly, in 26 healthy Caucasian male subjects.

\section{EXPERIMENTAL SECTION}

\section{Solvents and reference materials used}

All used solvents are of HPLC grade. Acetonitril and Methanol were purchased from VWR, formic acid from Merck KGaA, HPLC water was obtained using a Millipore Simplicity UV water purification system. Certified reference materials of Tadalafil and Losartan potassium (internal standardIS) were obtained from European Pharmacopoeia (Ph.Eur.), respectively Fluka and are of analytical standard grade. Blank human plasma was obtained from the regional blood transfusion center (CRTS) Cluj.

\section{Instrumentation and working parameters}

An Agilent 1200 series HPLC system with a Phenomenex Kynetex C18 column $(50 \times 2.10 \mathrm{~mm})$ equipped with Phenomenex Security Guard $(4 \times 2.0 \mathrm{~mm})$ was used for separation. The used mobile phase was an isocratic mixture of 30:70 acetonitrile:water (containing $0.1 \%$ formic acid). The used flow rate was $0.3 \mathrm{ml} / \mathrm{min}$, the column temperature was set to $45^{\circ} \mathrm{C}$. An Agilent 6410 triple Quadrupole Mass Spectrometer (Agilent Technologies, USA), equipped with electrospray ion source was used for the LC-MS/MS analyses. The runtime was $5 \mathrm{~min} / \mathrm{sample}$. The data acquisition and processing were carried out using MassHunter software. The whole system (software and hardware) was validated. The mass spectrometer was operated in positive ionization mode for analyte and IS. Nitrogen was used as nebulizing gas and collision cell gas. The temperature of the ESI source was set to $350^{\circ} \mathrm{C}$, and the needle voltage to $4000 \mathrm{~V}$. 
The quantitation was performed using MRM (multiple reaction monitoring) of the transitions: $\mathrm{m} / \mathrm{z} 390.2 \rightarrow 268.1,(390.2 \rightarrow 135.0$ qualifier ion) collision energy $15 \mathrm{~V}$, for tadalafil and $423.2 \rightarrow 207.1$ (423.2 $\rightarrow 377.2$ qualifier ion) collision energy $15 \mathrm{~V}$ for losartan (IS).

The mass spectrometer was operated at unit resolution with a dwell time of 300 ms per transition.

\section{Stock and working solutions preparation}

Stock solutions of tadalafil $(1.0 \mathrm{mg} / \mathrm{ml})$ were prepared in methanol dissolving accurately weighed amounts of reference material. Stock solutions of losartan-K $(1.0 \mathrm{mg} / \mathrm{ml})$ were prepared in methanol/water 50/50 (w/w) dissolving accurately weighed amounts of losartan-K. They were stored at $2-8{ }^{\circ} \mathrm{C}$. Correction factors were applied to the weighed amounts of reference materials to calculate the content of the pure substance (Table 3). Correction factors are derived from the purity and the chemical form (salt, etc.).

Table 3. Correction factors for reference materials

\begin{tabular}{|l|c|c|}
\hline Reference material & Tadalafil & $\begin{array}{c}\text { Losartan } \\
\text { potassium }\end{array}$ \\
\hline Purity (\%) & 99.9 & 99.6 \\
\hline Chemical form correction factor & 1.0000 & 0.9152 \\
\hline Correction factor & $\mathbf{0 . 9 9 9 0}$ & $\mathbf{0 . 9 1 1 5}$ \\
\hline
\end{tabular}

Working solutions of analyte and internal standard were prepared freshly before use by successive dilutions from stock solutions to appropriate levels, using methanol/water 50/50 (w/w) as solvent. They were used for spiking human plasma used for calibrators and QC samples preparation.

\section{Calibrators and QC samples preparation}

To $400 \mu \mathrm{l}$ of blank human plasma, $50 \mu \mathrm{l}$ of spiking solution of analyte and $50 \mu \mathrm{l}$ of spiking solution of internal standard were added in polypropylene tubes, to yield final concentrations of $22.23,44.45,83.35$, 166.70, 333.40, 611.23, 833.50, $1111.33 \mathrm{ng} / \mathrm{ml}$ for tadalafil.

\section{Sample preparation (workup)}

To precipitate plasma proteins, $2 \mathrm{ml}$ of methanol was added to the spiked samples, then vortexed for 20 minutes at $1500 \mathrm{rpm}$. Further the samples were centrifuged at $4{ }^{\circ} \mathrm{C}$ for 20 minutes at $4000 \mathrm{rpm} .450 \mu \mathrm{l}$ of supernatant was transferred to HPLC autosampler vials diluted with $450 \mu \mathrm{l}$ of water and injected into the analytical system ( $15 \mu \mathrm{l} / \mathrm{sample})$. 
VALIDATED LC-MS/MS METHOD FOR THE DETERMINATION OF TADALAFIL A COMPETITIVE PHOSPHODIESTERASE 5 INHIBITOR (PDE5) - FROM HUMAN PLASMA

\section{Calibration curve parameters}

The linearity of the method was evaluated using spiked plasma samples in the concentration range mentioned above using the method of least squares. Two identical validated analytical systems has been used, three linearity curves were analyzed on each system.

Each calibration batch (curve) consisted of: blank samples in duplicate, zero samples (blank with IS) in duplicate and eight non-zero concentration levels, of which the lower and upper limit of quantitation samples were in duplicate. The calibration curves were obtained by using a linear weighted (1/x) regression analysis of the peak area ratio (analyte/internal standard) versus the nominal concentration of the calibration standards. Study samples concentrations were obtained by interpolation from the calibration curve.

The linearity results are summarized in Table 2 in the 'Results and Discussion' section.

\section{ACKNOWLEDGMENTS}

This work was performed using private funding of S.C KYNETYX HT SRL.

\section{REFERENCES}

1. https://www.rxlist.com/cialis-drug.htm: CIALIS (tadalafil) Tablets; Viewed: 14.03.2019)

2. S. T. Forgue, B. E. Patterson, A. W. Bedding, C. D. Payne, D. L. Phillips, R. E. Wrishko, M. I. Mitchell, Br. J. Clin. Pharmacol., 2005, 61, 280.

3. N.V.S. Ramakrishna, K.N. Vishwottam, S. Puran, M. Koteshwara, S. Manoj, M. Santosh, J. Chidambara, S. Wishu, B. Sumatha, J. Chromatogr. B., 2004, 809, 243.

4. Bo Ma, Xuejun Shang, Qi Zhang, Jing Li, Yinhui Liu, Xiaomei Cao, Qiuyu Xu, J. Pharm. Biomed. Anal., 2013, 77, 149.

5. J. H. Lee, J.-H. Oh, Y.-J. Lee, Arch. Pharm. Res., 2013, 77, 457.

6. J.-M. Lee, J. Hong, H. B. Oh, B. Moon, Bull. Korean Chem. Soc., 2017, 39, 190.

7. K. Hasegawa, O. Suzuki, K. Gonmori, I. Yamagishi, H. Nozawa, K. Watanabe, Forensic Toxicol., 2012, 30, 25.

8. A. Bhadoriya, B. Dasandi, D. Parmar, P. A. Shah, P. S. Shrivastav, J. Pharm. Anal., 2018, 8, 271.

9. P. Nagaraju, B. Kodali, P. V. Datla, J. Pharm. Biomed. Anal., 2018, 152, 215.

10. L. Wang, Y. Wang, Y. Chai, Y. Kang, C. Suna, S. Zenga, J. Mass Spectrom., 2017, 52, 411. 
11. Y. Zhang, Z. Huang, L. Ding, H. Yan, M. Wang, S. Zhu, J. Sep. Sci., 2010, 33, 2109.

12. P. Zou, P. Hou, S. Sze-Yin Oh, M.-Y. Low, H.-L. Koh, Rapid Commun. Mass Spectrom., 2006, 20, 3488.

13. Fachinformation Cialis, Lilly, Stand. Mar. 2017, https://www.fachinfo.de

14. EMEA/CHMP/EWP/192217/2009 Rev. 1 Corr. $2^{* *}$ Guideline on validation of bioanalytical method, 21 July 2011 (Updated 03/06/2015). 